\title{
A PRECARIZAÇÃO DO TRABALHO DOCENTE NO ESTADO DE SÃO PAULO: 20 ANOS DE REFORMAS
}

\author{
LABOUR PRECARIOUS TEACHING IN SÃO PAULO STATE: \\ TWENTY YEARS OF REFORMS
}

\section{LA PRECARIZACIÓN DEL TRABAJO DOCENTE EN EL ESTADO DE SÃO PAULO: VEINTE AÑOS DE REFORMAS}

Patrícia Regina Piovezan ${ }^{1}$

Neusa Maria Dal $R i^{2}$

\begin{abstract}
RESUMO: Este trabalho tem por objetivo investigar as implicações das reformas educacionais, ocorridas nos últimos 20 anos, para a carreira da categoria docente do Estado de São Paulo. Partimos do pressuposto de que as novas políticas educacionais implantadas pela Secretaria de Educação do Estado de São Paulo, após a aprovação da Lei de Diretrizes e Bases da Educação Nacional no 9.394/96, aceleraram e ampliaram o processo de precarização do trabalho dos docentes paulistas em curso desde a década de 1970. Este estudo foi realizado por meio de pesquisa bibliográfica e documental, com análise das principais legislações relacionadas à temática. As principais categorias utilizadas na pesquisa foram a intensificação do trabalho docente, flexibilização nas formas de contratação e arrocho salarial. Ao longo da pesquisa localizamos e analisamos diversas legislações que permitem a intensificação e flexibilização das formas de contratação dos professores, assim como o arrocho salarial provocado por baixos salários e o incentivo à expansão de políticas que estimulam a remuneração dos docentes por meio de bonificação. Concluímos que uma série de reformas educacionais desenvolvida pelos governos federal e estadual paulista acelerou o processo de precarização do trabalho docente nas últimas duas décadas.
\end{abstract}

PALAVRAS-CHAVE: Reformas educacionais. Precarização do trabalho docente. Política educacional do Estado de São Paulo.

\begin{abstract}
This paper aims to investigate the implications of educational reform, in the last twenty years to the career of teaching category of São Paulo. We assume that the new educational policies implemented by the Education Department of the State of São Paulo, after approval of the Law of Directives and Bases of National Education $n^{\circ} .9 .394 / 96$, accelerated and expanded the precarious process of the work of São Paulo professors in ongoing since the 1970. This study was conducted through bibliographical and documentary research, with analysis of key legislation related to the theme. The main categories used in the survey were the intensification of teachers' work, flexibility in the ways of hiring and wage squeeze. During the research we locate and analyze various laws that allow for intensification and flexible forms of employment of teachers as well as the wage squeeze caused by low wages and encouraging the expansion of policies that encourage the employment of teachers through bonus. We conclude that a series of educational reforms developed by the São Paulo federal and state government accelerated the casualization process of teaching the last two decades.
\end{abstract}

KEYWORDS: Educational reforms. Labour precarious teaching. Educational policy of the State of São Paulo.

\footnotetext{
${ }^{1}$ Mestra em Educação pela Universidade Estadual Paulista "Júlio, de Mesquita Filho" - Campus de Marília, UNESP - Brasil. Doutoranda do Programa de Pós-Graduação em Educação pela mesma universidade. E-mail: patriciapiovezan8@hotmail.com.

${ }^{2}$ Livre-Docente pela Universidade Estadual Paulista “Júlio de Mesquita Filho" - Campus de Marília e doutora em Educação pela Universidade de São Paulo, USP - Brasil. Professora associada do Departamento de Administração e Supervisão Escolar da Universidade Estadual Paulista "Júlio de Mesquita Filho" - Campus de Marília, UNESP - Brasil. E-mail: neusamdr@terra.com.br.
}

Recebido em: 24/05/2015 - Aprovado em: 03/12/2015.

\begin{tabular}{l|l|l|l|l|l|l} 
(C) ETD-Educ. Temat. Digit. & Campinas, SP & v.18 & n.1 & p. 178-197 & jan./abr. 2016 & ISSN 1676-2592
\end{tabular}


RESUMEN: Este trabajo tiene como objetivo investigar las implicaciones de la reforma educativa, en los últimos veinte años en la carrera de la categoría docente de São Paulo. Suponemos que las nuevas políticas educativas implementadas por la Secretaría de Educación del Estado de São Paulo después de la aprobación de la Ley de Directrices y Bases de la Educación Nacional $\mathrm{n}^{\circ}$ 9.394/96, aceleraron y ampliaron el proceso de precarización del trabajo de los profesores de São Paulo en curso desde la década de 1970. Este estudio se llevó a cabo a través de la investigación bibliográfica y documental, con el análisis de la legislación clave relacionada con el tema. Las principales categorías utilizadas en la encuesta fueron la intensificación del trabajo de los profesores, la flexibilidad en las formas de contratación y el apretón de salarios. Durante la investigación que localizar y analizar diversas leyes que permitan la intensificación y formas flexibles de empleo de los docentes, así como la restricción salarial causada por los bajos salarios y el fomento de la expansión de las políticas que fomenten el empleo de los maestros a través de bonos. Llegamos a la conclusión de que una serie de reformas educativas desarrolladas por el gobierno federal y el estado de São Paulo se aceleró el proceso de precarización de los docentes de las dos últimas décadas.

PAlAVRAS ClaVE: Reformas educativas. Precarización del trabajo docente. Política educativa del Estado de São Paulo.

\section{INTRODUÇÃO}

A precarização do trabalho docente, fenômeno em desenvolvimento no Brasil desde o regime militar, tem apresentado um processo de intensificação desde a década de 1990 até os dias atuais. A precarização é um fenômeno presente em diversas categorias de trabalhadores, no entanto, para esta pesquisa investigamos o percurso e o processo de precarização do trabalho dos professores que lecionam nas escolas estaduais da rede pública paulista. Desse modo, neste texto temos como objetivo mostrar que as novas políticas educacionais implantadas pela Secretaria de Educação do Estado de São Paulo, após a aprovação da Lei de Diretrizes e Bases da Educação Nacional n. ${ }^{\circ}$ 9.394/96 (LDBEN), aceleraram e ampliaram o processo de precarização do trabalho dos docentes paulistas.

Segundo Alves (2007, p. 114) o trabalho precário é inerente à ordem capitalista por causa de duas características embrionárias dessa forma de trabalho: a alienação e o assalariamento, de modo que “[...] a precarização é um processo que possui uma irremediável dimensão histórica determinada pela luta de classes e pela correlação de forças políticas entre capital e trabalho". Entretanto, apesar da essência da precariedade do trabalho no sistema capitalista de produção, para Alves (2007, p. 115), as últimas quatro décadas revelaram um avanço no processo de precarização do trabalho, tendo em vista a corrosão dos direitos trabalhistas e a intensificação do trabalho nesse período. Assim sendo, “[...] o que chamamos de processo de precarização do trabalho é o processo de diluição (ou supressão) dos obstáculos constituídos pela luta de classe à voracidade do capital no decorrer do século XX”.

O desmonte dos direitos trabalhistas conquistados historicamente pela classe trabalhadora ao longo dos séculos XIX e XX é um fenômeno que integra e amplia o processo de precarização do trabalho desencadeado em decorrência da reestruturação produtiva e da financeirização do capital, que baseadas no modelo de acumulação flexível de produção intensificou o volume de trabalho, as formas precárias de contratação e a velocidade da produção. 
A lógica do capital dos últimos 40 anos tem atingido diversas categorias de trabalhadores, tanto aquelas que realizam um trabalho manual, quanto as que realizam um trabalho intelectual, dentre elas, a categoria docente. Assim, abordamos neste trabalho a implicação das reformas das políticas educacionais paulistas na ampliação do processo de precarização do trabalho docente, haja vista que as legislações são norteadoras desse processo e estão em consonância com as novas tendências produtivas.

\section{MÉTODO}

Para a pesquisa bibliográfica selecionamos várias obras, teses, dissertações, artigos, reportagens e boletins que abordam a temática sobre a precarização do trabalho docente e, especificamente, aquelas relacionadas com as categorias pertinentes à pesquisa. Para a pesquisa documental selecionamos diversas leis, decretos e resoluções federais e, em especial, as leis e decretos estaduais paulistas promulgadas nos últimos anos, que apresentam temas, tais como: piso salarial; jornada de trabalho; formas de contratação; bonificações etc.

Para demonstrarmos a hipótese da relação entre as reformas educacionais e a ampliação do processo de precarização do trabalho docente, selecionamos três categorias, a intensificação do trabalho docente, a flexibilização nas formas de contratação dos professores e o arrocho salarial. Essas categorias foram norteadoras para a seleção da literatura perquirida e legislações analisadas.

\section{AS DÉCADAS DE OURO E A PRECARIZAÇÃO DO TRABALHO DOCENTE NOS ANOS DE 1970 E 1980}

Designamos de 'décadas de ouro' da profissão docente os anos de 1940 e 1950, pois foi nesse período que o Estado proporcionou aos professores melhores condições de trabalho quando comparadas às décadas posteriores. As principais características que geraram a denominação dos 'anos de ouro' foram a então reduzida jornada de trabalho, o controle do processo de trabalho, prestígio social e os dignos salários dos professores. Entretanto, essas condições de trabalho apenas eram possíveis em razão do acesso limitado ao ensino público e às classes sociais que frequentavam a escola.

Distinta da realidade atual das escolas, que atendem um público formado por alunos e professores de diferentes classes sociais, na década de 1940 tanto os docentes quanto os alunos pertenciam, em sua grande maioria, à elite ou às classes médias, tendo em vista a origem e a função social dos alunos que ingressavam nas escolas públicas naquele período. Desse modo, "A tradição do antigo Ginásio pode ser resumida nos seguintes aspectos: seleção e formação da futura elite dirigente do estado e do país; ensino de alto padrão como pressuposto desta formação" (MONFREDINI, 2008, p. 125).

As condições de trabalho e financeiras dos professores os situavam "[...] na 'classe média' assalariada, tanto pela origem, uma vez que 69,5\% dos pais dos professores exerciam atividades assalariadas não-manuais - sendo que $10 \%$ eram pequenos proprietários -" (PESSANHA, 2001, p. 87). Assim, lecionar para as crianças e jovens oriundos das classes 
abastadas exigia que os professores possuíssem prestígio social e condições financeiras para atender às necessidades de formação dos jovens da elite.

Em relação ao controle do processo de trabalho, Vicentini e Lugli (2009, p. 82) apontam que a autonomia dos docentes na organização das aulas e da escola era de tamanha amplitude que as determinações assumidas pelos mesmos contemplavam desde a seleção dos alunos até as bancas de concursos para ingresso na carreira docente.

\section{[...] cada estabelecimento possuía grande autonomia pedagógica, o que significava que as decisões quanto à seleção de alunos, escolha de livros-texto, questões disciplinares, e nomeação de bancas de concurso, entre outras, eram tomadas pela Congregação de docentes.}

Desse modo, o professor exercitava o poder de cátedra integralmente, tendo em vista que decidia acerca dos conteúdos que ministrava e das atividades que realizaria na sala de aula, bem como o tempo que levaria para efetivar tais atividades, de modo que o docente poderia "[...] aplicar provas; aprovar e reprovar alunos com arbitrariedade; indicar bibliografias e outros materiais didáticos; registrar os temas do programa em seu diário de classe e tratar de outros assuntos" (VIEITEZ; DAL RI, 2011, p. 150).

Por fim, ressalvamos a reduzida carga horária letiva dos docentes secundários paulistas, em torno de 12 horas semanais. Contudo, na década de 1960, a quantidade de aulas foi contestada pelo então governador Carvalho Pinto, sugerindo à Assembleia Legislativa “[...] o Projeto n. ${ }^{\circ} 1.048$, segundo o qual o número de aulas ordinárias passaria de 12 para 18 por semana e de 50 para 81 por mês" (VICENTINI; LUGLI, 2009, p. 132), e um forte arrocho salarial "[...] de modo que o professor - cujo salário era de Cr\$23.465,00 por 50 aulas mensais; portanto, $\mathrm{Cr} \$ 469,30$ por aula - passaria a receber $\mathrm{Cr} \$ 33.800,00$ por 81 aulas mensais, o equivalente a Cr\$ 417,20 por aula” (VICENTINI; LUGLI, 2009, p. 132).

Para Vicentini e Lugli (2009), as reformas políticas que precarizavam o trabalho docente entraram em curso no Estado de São Paulo já no início dos de 1960, antes do golpe militar de 1964, destacando o pioneirismo de São Paulo no processo de corrosão dos direitos da categoria docente. Nos anos de 1970 e 1980, o processo de precarização do trabalho docente foi ampliado por motivo de três ações conjuntas: o arrocho salarial; a expansão das contratações dos docentes; e as formas flexíveis dessas contratações.

As décadas de 1970 e 1980 marcaram o fim dos 'anos de ouro' da carreira docente, em especial pela expansão realizada após a Lei de Diretrizes e Bases n. ${ }^{\circ}$ 5.692/71, que aumentou a obrigatoriedade da escolaridade de quatro para oito anos. Apesar da relevância e da necessidade da expansão do ensino no Brasil, ela foi realizada à custa da precarização dos direitos trabalhistas dos docentes, uma vez que não 'era possível', de acordo com as verbas destinadas à educação, expandir as contratações dos professores mantendo o mesmo padrão de jornada de trabalho e nível salarial.

Segundo Vianna (1999) a redução e a corrosão inflacionária dos salários dos professores provocaram um aumento do número de aulas lecionadas, porém, nem mesmo esse subterfúgio foi suficiente para que os professores compensassem as perdas salariais. 
O arrocho salarial foi uma das marcas registradas da política econômica do regime militar. Nos conjunto dos assalariados oriundos das classes médias, o professorado do ensino básico foi um dos mais atingidos pelas medidas econômicas que reduziram drasticamente a massa salarial dos trabalhadores brasileiros (FERREIRA JUNIOR; BITTAR, 2006, p. 70).

Segundo Jesus (2004, p. 195), a aligeirada elevação na contratação dos docentes “[...] traduziu-se na 'massificação do ensino', originando o aumento brusco do número de alunos, de escolas e, necessariamente, de professores". Esse fato exigiu, ainda, que muitos professores elevassem a sua jornada de trabalho, bem como a quantidade de escolas para lecionarem, de forma que os docentes "[...] tiveram que começar a deslocar-se entre escolas para sobreviver, o que quebrou os vínculos das equipes com os seus estabelecimentos, prejudicando a qualidade do trabalho pedagógico"i (VICENTINI; LUGLI, 2009, p. 83).

Outra medida do governo militar para tentar equilibrar o número de professores em acordo com a expansão das matrículas foi a de flexibilizar as formas de contratação, assim como aligeirar a sua formação e estender a contratação de professores com a escolaridade mínima para o exercício da profissão. Para Vianna (1999, p. 90) a flexibilização nas formas de contratação dos professores gerou "[...] um contingente significativo da categoria contratado sem concurso, em caráter excepcional e em caráter temporário - docentes conhecidos como precários".

Portanto, é passível de observação que o processo de precarização do trabalho docente, especialmente dos professores da rede pública paulista, teve início há mais de 40 anos. Ainda, ressaltamos o pioneirismo da precarização do trabalho docente no Estado de São Paulo não apenas na década de 1960, mas na década de 1990, momento histórico de retomada e avanço da precarização do trabalho docente, após uma breve pausa nesse processo em decorrência das lutas sindicais dos anos de 1980.

\section{A RETOMADA DO PROCESSO DE PRECARIZAÇÃO DO TRABALHO DOCENTE NO ESTADO DE SÃO PAULO: DA DÉCADA DE 1990 AOS DIAS ATUAIS}

Os anos de 1980 foram marcados pela luta de movimentos sociais e de trabalhadores contra a ditadura militar e pela redemocratização do país, o que resultou na elaboração e aprovação de uma nova Constituição Federal. Variadas manifestações, paralisações e greves realizadas por trabalhadores de diversos setores impulsionaram a incorporação de direitos sociais na Constituição de 1988, e no que diz respeito a este trabalho, em especial, o direito de sindicalização e de greve dos funcionários públicos.

Ao longo da década de 1960 e 1970, a principal entidade paulista de professores, a Associação dos Professores do Ensino Oficial do Estado de São Paulo (APEOESP), teve sua atuação prejudicada em decorrência da repressão e do autoritarismo do regime militar. Contudo, em 1978, a primeira greve realizada pelos professores paulistas resultou em 
conquistas de direitos, o que aumentou o poder das ações da entidade, expandindo, consideravelmente, a quantidade de filiados à Associação no decorrer da década de 1980.

\begin{abstract}
Entre as entidades representativas do magistério no ensino público, a Apeoesp adquiriu grande visibilidade ao longo da década de 80 . O número de associados, a participação dos professores nas mobilizações por ela lideradas e a extensão de seu patrimônio assim o indicam. Em 1980, a entidade possuía 19 mil associados, distribuídos em 18 subsedes no Estado de São Paulo; 10 anos depois, em 1989, contava com 65 mil associados em 57 subsedes (VIANNA, 1999, p. 94).
\end{abstract}

Os anos de 1980 foram simbólicos não apenas para os docentes paulistas que conquistaram uma série de direitos, mas também para o magistério nacional, tendo em vista a criação, em 1988, do Fórum Nacional em Defesa da Escola Pública do qual participavam 25

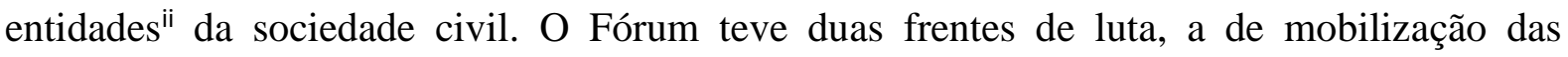
categorias para as manifestações e a de negociação parlamentar, o que resultou em algumas conquistas, tais como a criação do plano de carreira do magistério, a aprovação de piso salarial para a categoria e a gestão democrática na escola pública. Os três itens foram integrados à Lei de Diretrizes e Bases da Educação Nacional aprovada em 1996. Em relação ao professorado paulista,

Entre as reivindicações vitoriosas encontram-se 5 referências salariais obtidas na greve de 1984; 6 referências e 25\% de reajuste salarial, em 1986; 4 gatilhos salariais, em 1987; transformação do abono fixo de NCr\$27,00 em percentual de $18 \%$ sobre a carreira, estendido também aos professores aposentados, em 1988, e um reajuste salarial de $51 \%$ a $126 \%$, com maiores vantagens para os professores de nível 1 (PI) em 1989 (VIANNA, 1999, p. 95).

Apesar do forte movimento desencadeado pelas entidades e sindicatos no final dos anos de 1970 e nos anos de 1980, na década seguinte ocorreu, por um lado, o descenso do movimento popular e de trabalhadores e, por outro lado, a retomada do processo de precarização do trabalho dos professores. Destacamos três fenômenos que constituíram parte das medidas que deram origem à ampliação do processo de precarização no Estado de São Paulo: a intensificação do trabalho; a flexibilização nas formas de contratação dos professores; e o arrocho salarial.

A intensificação do trabalho docente é um fenômeno ocorrido nos últimos 20 anos em consequência do aumento do volume de atividades realizadas pelos professores dentro e fora da sala de aula. $\mathrm{O}$ aumento no número dessas atividades ocorre em razão da expansão da quantidade de aulas lecionadas semanalmente, ao número de escolas nas quais os docentes trabalham e à quantidade de alunos que cada professor atende.

A intensificação do trabalho dos professores acontece dentro e fora da sala aula por causa da quantidade de aulas que os professores lecionam diariamente gerando, consequentemente, um aumento significativo no número de alunos atendidos e um aumento do volume de atividades extraclasse realizadas, entre elas, o preparo de aulas, correção de trabalhos e provas, atendimento aos alunos, preenchimento de formulários e diários de classe etc. 
Segundo Kuenzer e Caldas (2009, p. 35), uma das formas visíveis da intensificação do trabalho docente é a sensação de que o professor já não possui tempo ${ }^{\mathrm{iii}}$ para realizar outras tarefas corriqueiras do seu ambiente de trabalho para além daquelas executadas na sala de aula, dentre as quais, "[...] não ter tempo sequer para ir ao banheiro, tomar uma xícara de café, até uma falta total de tempo para conservar-se em dia com sua área".

A partir de uma pesquisa realizada pela Apeoesp (2011), que visou compreender as condições de saúde dos professores da rede estadual paulista, apresentamos dois gráficos que ilustram a carga horária semanal dos docentes e o número de períodos que os mesmos trabalham diariamente.
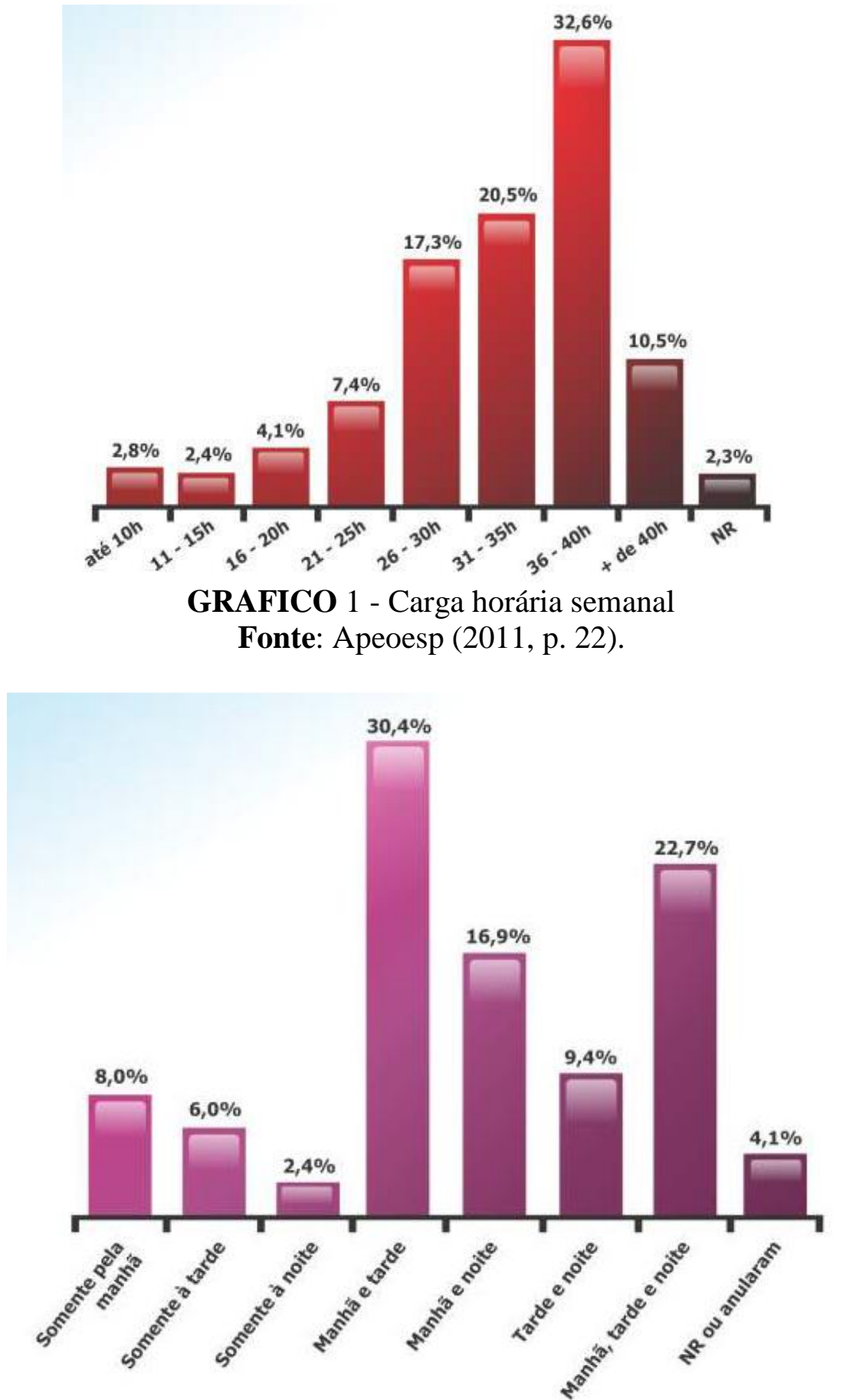
GRÁFICO 2 - Períodos em que leciona

Fonte: Apeoesp (2011, p. 26).

No primeiro gráfico, que apresenta a quantidade de horas de trabalho acumuladas semanalmente por cada professor, observamos que a maior porcentagem de professores trabalha entre 36 e 40 horas semanais $(32,6 \%)$. Esse um terço dos professores que trabalham entre 36 e 40 horas ao longo da semana tem a carga horária máxima indicada pela Lei n. ${ }^{\circ}$ 11.738 , de 16 de julho de 2008, que institui o piso salarial profissional nacional para os profissionais do magistério público da educação básica. Apesar de 10,5\% dos docentes afirmarem trabalhar mais de 40 horas semanais, expondo a condição de intensificação do trabalho desses profissionais, esses dados não demonstram o impacto no aumento da jornada de trabalho dos docentes após a aprovação do Decreto n. ${ }^{\circ}$ 59.448, de 19 de agosto de 2013, que será abordado em seguida neste texto ${ }^{\text {iv }}$.

A partir dos dados apresentados no segundo gráfico, observamos que a minoria dos professores $(16,4 \%)$ trabalha apenas um período ao longo do dia, e aqueles que trabalham em dois períodos diários representam majoritariamente a categoria somando 56,7\%, enquanto $22,7 \%$ trabalham no decorrer dos 3 períodos (manhã, tarde e noite). Desse modo, $79,4 \%$ dos docentes pesquisados trabalham dois ou três períodos diariamente, restando-lhes pouco ou nenhum tempo livre para realizar outros tipos de atividade.

Atentemos também para o fato de que a possibilidade de os professores acumularem maior número de aulas, escolas e períodos de trabalho advém das legislações que permitem esse tipo de acúmulo, como, por exemplo, a Emenda Constitucional n. ${ }^{\circ} 19$, de 4 de junho de 1998, que modificou o regime e dispôs sobre os princípios e normas da Administração Pública. No artigo $3^{\circ}$ da referida Lei, consta que:

XVI - é vedada a acumulação remunerada dos cargos públicos, exceto, quando houver compatibilidade de horários, observado em qualquer caso o disposto no inciso XI:
a) a de dois cargos de professor
b) a de um cargo de professor com outro, técnico ou científico
c) a de dois cargos privativos de médico (BRASIL, 1998, p. 1).

Além de a intensificação do trabalho provocar consequências negativas para a vida e saúde do professor, reduzindo o seu tempo de descanso e lazer, configura-se como um ataque à autonomia e condições de trabalho e à disponibilidade para o aprimoramento profissional, pois o excesso de trabalho realizado restringe, cada vez mais, o tempo necessário para discutir, criar e efetuar um projeto escolar coletivo, haja vista que a maioria dos professores vivencia a mesma condição de intensificação do trabalho.

A intensificação do trabalho docente modifica a morfologia do trabalho desse profissional, uma vez que diversos aspectos da sua vida profissional e pessoal são alterados, implicando

[...] uma sensação crônica de sobrecarga de trabalho (mais e mais para ser feito em tempo cada vez menor para fazer o que deve ser feito), o que reduz áreas de decisão pessoal, envolvimento e controle sobre planejamento, aumenta a dependência de materiais e especialistas externos ao trabalho, provocando maior separação entre concepção e execução, entre planejamento e desenvolvimento); iv) reduz a 
qualidade do tempo (para se 'ganhar' tempo somente o 'essencial' é realizado), o que aumenta o isolamento, reduz a interação e limita a reflexão conjuntiva; v) as habilidades coletivas de trabalho são perdidas ou reduzidas e as habilidades de gerência são incrementadas; vi) impõe e incrementa o trabalho de especialistas para dar cobertura a 'deficiências' pessoais; vii) introduz soluções técnicas simplificadas (tecnologias) para mudanças curriculares, a fim de compensar o reduzido tempo de preparo (planejamento); viii) as formas de intensificação são muitas vezes interpretadas como profissionalização e, assim, passam a ser voluntariamente apoiadas pelo magistério (DEL PINO; VIEIRA; HYPOLITO, 2009, p. 123-124).

A flexibilização das formas de contratação dos docentes é outro fenômeno crescente propiciado pelas reformas educacionais promovidas pelos governos federal e paulista. As principais formas de contratos são em tempo determinado ou eventual. Uma das primeiras legislações federais que permitiram as formas flexíveis de contratações dos professores foi aprovada no início da década de 1990, por meio da Lei n. ${ }^{\circ} 8.745$, de 9 de dezembro de 1993, que dispõe sobre a contratação por tempo determinado.

Art. $2^{\circ}$ Considera-se necessidade temporária de excepcional interesse público:

IV - admissão de professor substituto e professor visitante;

VII - admissão de professor, pesquisador e tecnólogo substitutos para suprir a falta de professor, pesquisador ou tecnólogo ocupante de cargo efetivo, decorrente de licença para exercer atividade empresarial relativa à inovação (BRASIL, 1993, p. 1).

Ainda nos anos de 1990, a Emenda Constitucional n. ${ }^{\circ}$ 19, já citada, permitiu a flexibilização da contratação do docente possibilitando o acúmulo de cargos públicos, que autoriza a conciliação entre dois cargos de professor ou mesmo um cargo de professor e outro de técnico ou científico.

As leis citadas contribuem para a propagação de dois fenômenos: a inserção em massa de docentes contratados em caráter temporário; e o aumento no acúmulo de aulas para cada docente, tendo em vista a possibilidade do acúmulo de cargos, gerando a intensificação do trabalho docente.

Em relação às legislações paulistas, especificamente, o primeiro decreto criado para possibilitar a contratação flexível foi promulgado na década de 1980. O Decreto n. ${ }^{\circ} 24.948$, de 3 de abril de 1986, foi desenvolvido para regulamentar a contratação de uma categoria de professores denominada de eventuais ou categoria I. De acordo com Aranha (2007), a precariedade dos professores desta categoria ocorria porque não participavam do processo de atribuição de aulas; necessitavam esperar que a escola os convocasse para substituir um professor, caso houvesse vagas; a admissão do contrato em caráter eventual não constitui vínculo trabalhista e, por fim, porque o professor eventual recebia remuneração pelo número de aulas lecionadas.

Outra flexibilização das contratações dos professores eventuais surgiu a partir da reformulação do Decreto de 1986. Trata-se da Resolução SE nº 134/2003, que dispõe sobre o processo anual de atribuição de classes e aulas ao pessoal docente, ressalvando no seu artigo $7^{\circ}$ mais um elemento propulsor da flexibilização na contratação, pois permite aos inscritos no processo de atribuição de aulas lecionarem disciplinas que não fazem parte da sua área de 
formação, bem como a possibilidade de concorrer à seleção aqueles que são bacharéis, portadores de diploma de licenciatura curta ou tecnólogos.

$\S 7^{\circ}$ - Poderão fazer inscrições, tanto na Unidade Escolar, quanto na Diretoria de Ensino, conforme o caso, não apenas os docentes ou candidatos devidamente habilitados, mas também os portadores de diploma de licenciatura curta, os alunos do último ano de cursos regulares de licenciatura plena e os bacharéis ou tecnólogos de nível superior, observadas, em relação à inscrição na unidade escolar, as condições previstas no $\S 2^{\circ}$ deste artigo (SÃO PAULO, 2003, p. 1).

Em relação à lei estadual que permite a contratação de professores por tempo determinado ou da denominada categoria O, a Lei Complementar . $^{\circ} 1.093$, de 16 de julho de 2009, baseada no inciso X do artigo 115 da Constituição Estadual, estabelece no artigo $1^{\circ}$ que será possível este tipo de contratação, caso ocorram as seguintes situações:

IV - para suprir atividade docente da rede de ensino público estadual, que poderá ser feita nas hipóteses previstas no inciso II deste artigo e, ainda, quando:

a) o número reduzido de aulas não justificar a criação de cargo correspondente;

b) houver saldo de aulas disponíveis, até o provimento do cargo correspondente;

c) ocorrer impedimento do responsável pela regência de classe ou magistério das aulas (SÃO PAULO, 2009, p. 01).

Outra legislação estadual que contribui para a intensificação e flexibilização do trabalho docente é o Decreto n. 59.448, de 19 de agosto de 2013, aprovado pelo governador Geraldo Alckmin, que dispõe sobre as jornadas de trabalho do pessoal docente do quadro do magistério. Segundo o decreto, os docentes podem acumular a abusiva jornada de trabalho de 65 horas de trabalho semanais.

Art. 12 - A acumulação remunerada de dois cargos docentes ou duas funções docentes ou de um cargo de suporte pedagógico com um cargo ou função docente poderá ser exercida, desde que:

I - seja observado o limite de 65 (sessenta e cinco) horas semanais para a carga horária total do acúmulo;

II - haja publicação de ato decisório favorável, após verificação da compatibilidade de horários, observada a distância entre os órgãos/unidades (SÃO PAULO, 2013, p. 1).

Desse modo, com base na análise das legislações citadas, afirmamos que a flexibilização nas formas de contratação dos docentes levou ao significativo aumento do número de contratações de professores eventuais e temporários, em especial, no Estado de São Paulo. Segundo Lapo e Bueno (2003, p. 68), em 1995 os professores efetivos paulistas correspondiam a "[...] apenas $34 \%$ do total de professores da rede, uma vez que os $66 \%$ restantes eram docentes contratados a título precário, por tempo determinado".

Na década seguinte os números não eram diferentes. Conforme os estudos de Moura (2013, p. 66): "Em agosto de 2005, havia 138.650 professores efetivos lecionando nas escolas públicas e 114.264 professores ACTs". Outros dados que corroboram para a elevação na contratação dos docentes paulistas em caráter temporário foram apresentados por pesquisa do DIEESE realizada em 2007. 
TABELA 1 - Situação Funcional dos Professores da Rede Estadual Janeiro - 2007

\begin{tabular}{|c|c|c|c|c|c|c|}
\hline \multirow[b]{2}{*}{ QM } & \multicolumn{2}{|c|}{ Efetivo } & \multicolumn{2}{|l|}{ OFA } & \multicolumn{2}{|c|}{ Total } \\
\hline & $\mathrm{N}^{\circ}$ & $\%$ & $\mathrm{~N}^{\mathrm{o}}$ & $\%$ & $\mathrm{~N}^{\circ}$ & $\%$ \\
\hline PEB I & 29.591 & $43,5 \%$ & 38.483 & $56,5 \%$ & 68.074 & $100 \%$ \\
\hline P II & - & - & 147 & $100,0 \%$ & 147 & $100 \%$ \\
\hline PEB II & 81.588 & $56,5 \%$ & 62.936 & $43,5 \%$ & 144.524 & $100 \%$ \\
\hline Total & 111.179 & $52,3 \%$ & 101.566 & $47,7 \%$ & 212.745 & $100 \%$ \\
\hline
\end{tabular}

Fonte: Dieese (2007, p. 07).

Em dados mais recentes, Takahashi (2014, não paginado) aponta que ao longo da gestão do Governador Geraldo Alckmin “[...] o contingente de docentes temporários mais que dobrou e agora representa $24 \%$ do total de professores. São quase 40 mil temporários a mais, num período em que foram chamados pelo Estado 37 mil concursados".

Desse modo, a flexibilização nas formas de contratação dos docentes é possível graças a uma série de legislações que permitem essas formas de contratação, gerando o aumento da admissão dos docentes em tempo parcial ou em jornada reduzida; em caráter temporário; distribuição de aulas para professores eventuais; ampliação da jornada de trabalho; acúmulo de dois cargos etc.

Por fim, o arrocho salarial é outra medida de precarização do governo paulista que vem sendo tomada nesses últimos 20 anos. Nas décadas de 1970 e 1980, Garcia e Anadon (2009, p. 68) já verificavam a regressão dos salários dos professores do ensino básico nos estados de São Paulo e Rio de Janeiro.

[...] em 1967, os professores primários da rede estadual de São Paulo recebiam um salário médio por hora equivalente a 8,7 vezes o salário mínimo; em 1979, essa média já tinha baixado para 5,7 vezes. No Rio de Janeiro, com uma série de tempo mais longa, em 1950, os professores recebiam por hora 9,8 vezes o salário mínimo da época; em 1960, essa média já tinha baixado para 4 vezes; em 1977, cai para 2,8 e, por último, em 1990, já estava em 2,2 salários mínimos.

Conforme a citação, nos anos de 1990 o salário do professor havia sido arrochado a ponto de alcançar 2,2 salários mínimos, ou seja, 1/4 da remuneração de um docente que lecionava na década de 1960. No início da década de 1990, antes da aprovação da LDBEN em 1996, havia uma expectativa em relação à questão salarial dos docentes, especialmente, referente ao piso salarial, em razão das reivindicações dos movimentos em defesa da educação pública dos anos de 1980.

A exigência do piso salarial foi incluída na Constituição Federal de 1988, no artigo 206, firmando no inciso VIII o "[...] piso salarial profissional nacional para os profissionais da educação escolar pública, nos termos de lei federal” (BRASIL, 1988, p. 121), assim como 
no inciso III do artigo $67^{\circ}$ da LDBEN n. ${ }^{\circ}$ 9.394/96. Contudo, destacamos que na década de 1990 não ocorreram os esperados progressos na condição salarial dos docentes, conforme previsto nas leis.

A Lei n. ${ }^{\circ} 11.738$, de 16 de julho de 2008, que determinou o piso salarial dos professores, somente foi aprovada 20 anos após a promulgação da Constituição Federal de 1988, e 12 anos após a LDBEN. Entretanto, o piso salarial determinado foi considerado baixo pela categoria docente, pois o salário mínimo fixado para a jornada máxima de 40 horas semanais foi de $\mathrm{R} \$ 950,00$, quando o salário mínimo nacional, em 2009, era de $\mathrm{R} \$ 465,00$.

Em relação ao arrocho salarial no Estado de São Paulo podemos verificar, conforme a tabela 1, que entre 1995 e 1999, mesmo que o salário dos professores equivalesse a duas vezes o valor do salário mínimo nacional, de acordo com o piso do DIEESE, os salários dos docentes estavam defasados perante a renda necessária para um assalariado, conforme indicam os dados da tabela:

TABELA 2 - São Paulo: salários dos professores estaduais (1995-1999)

\begin{tabular}{|c|c|c|c|c|c|c|c|c|}
\hline $\begin{array}{l}20 \text { horas ol grat } \\
\text { e complemento }\end{array}$ & PUPEB 1 & $\begin{array}{r}\text { Hora } \\
\text { aula }\end{array}$ & PII & Hora aula & PIIIPEB 2 & Hora aula & $\begin{array}{r}\text { Piso } \\
\text { DIEESE }\end{array}$ & $\begin{array}{l}\text { Salário } \\
\text { Minimo }\end{array}$ \\
\hline Março/1995 & 180,00 & 1,80 & 197,16 & 1,97 & 216,08 & 2,16 & & \\
\hline Março/1996 & 238,55 & 2,38 & 261,72 & 2,61 & 287,26 & 2,87 & 801,95 & 112,00 \\
\hline Marcol1997 & 286,55 & 2,86 & 309,72 & 3,09 & 335,27 & 3,35 & 863,71 & 120,00 \\
\hline $\begin{array}{l}24 \text { horas } \\
\text { (Marcol98 }\end{array}$ & 488,00 & 4,06 & & & 610,00 & 5,08 & 942,09 & 130,00 \\
\hline Abril/1999 & 488,00 & 4,06 & & & 610,00 & 5,08 & 878,24 & 130,00 \\
\hline
\end{tabular}

Fonte: Souza (1999, p. 169).

Em 2010 o salário mínimo nacional estava fixado em $\mathrm{R} \$ 510,00$, enquanto a média dos salários dos professores paulistas, nesse período, conforme o gráfico 3, estava entre $\mathrm{R} \$$ $1.201,00$ e $\mathrm{R} \$ 2.4000$, de acordo com $57 \%$ dos professores pesquisados. Contudo, não há discriminação de qual era a porcentagem de docentes que possuíam a remuneração de 3 a 4 salários mínimos, por exemplo. Apesar de o salário dos professores paulistas estar um pouco acima do piso salarial, que em 2010 era $\mathrm{R} \$$ 1024,67, para o DIEESE (2011) a média do salário mínimo necessário nesse ano seria de $\mathrm{R} \$ 2.110,26$, valor que apenas $1 / 4$ dos docentes paulistas recebeu naquele ano. 


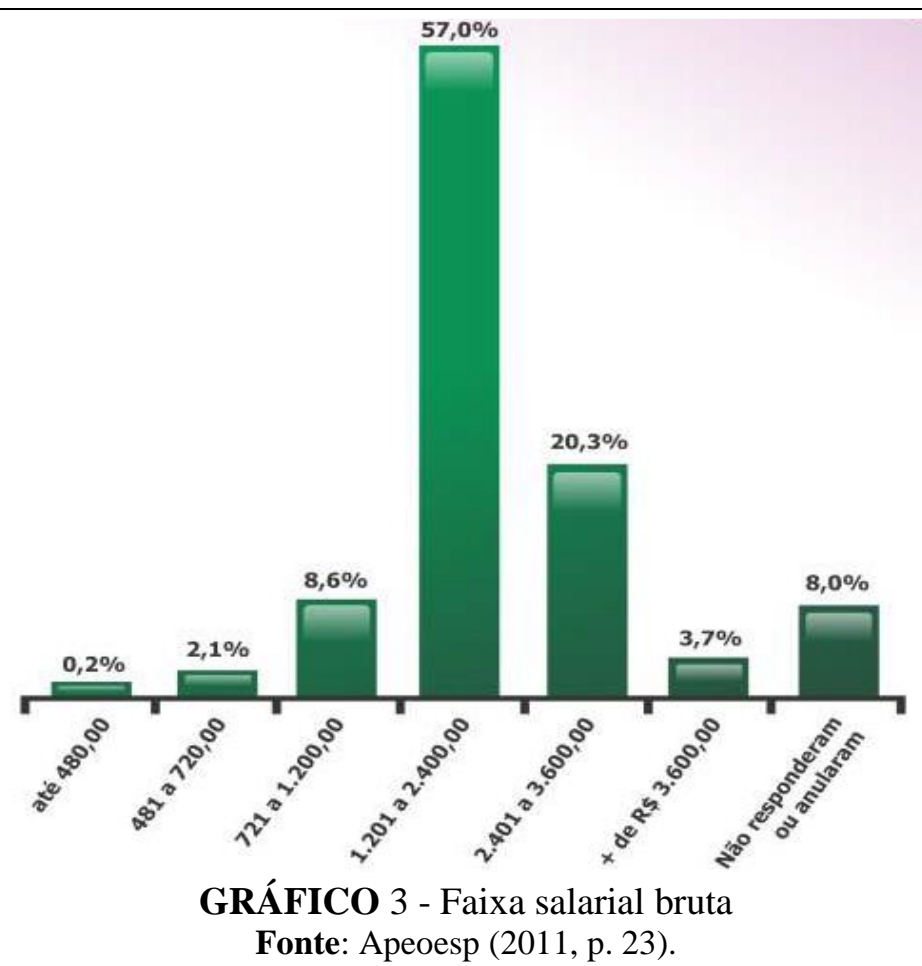

Em julho de 2014, o salário-base de um professor de educação básica II, no Estado de São Paulo, estava fixado em R \$ 2.415,89, com um valor de hora aula de R \$ 12,08 (APEOESP, 2014). Nesse mesmo período, o valor do salário mínimo necessário segundo o DIEESE (2014), era de R \$ 2.915, 07, corroborando a histórica defasagem no salário dos professores paulistas.

Uma das medidas adotadas no Estado de São Paulo para 'elevar' a remuneração dos professores foi o emprego de bonificações condicionadas aos resultados obtidos pelos docentes nas variadas formas de avaliação que são aplicadas nas escolas. De acordo com Torres (2007, p. 166), vincular o salário dos docentes aos resultados obtidos é uma das indicações propostas pelos técnicos do Banco Mundial, na década de 1990, afirmando que "[...] os salários dos professores devem se vincular ao desempenho e esse deve ser medido através do rendimento dos alunos".

Além da bonificação vinculada aos bons resultados atingidos pelos alunos nas avaliações, outros critérios adotados para 'estimular' os professores a alcançarem o valor máximo do bônus foram a assiduidade do docente, o cumprimento das metas estabelecidas para o estabelecimento de ensino, o desempenho das escolas diante dos indicadores e os dias de efetivo exercício dos professores.

Assim, aprovou-se no Estado de São Paulo a primeira lei instituindo o bônus mérito para os docentes do quadro do magistério, Lei Complementar n. ${ }^{\circ} 891$, de 28 de dezembro de 2000. Essa lei não apontava exigência alguma para os docentes associada ao número de faltas ou desempenho dos alunos, porém, já destacava que o bônus de $\mathrm{R} \$ 750,00$ seria pago uma vez por ano para os docentes que cumpriam a carga horária de 40 horas semanais. 
Destacamos ainda o artigo $6^{\circ}$ dessa Lei que determina que "A importância paga a título de Bônus Mérito não se incorpora aos vencimentos ou salários para nenhum efeito, e não será considerada para cálculo de qualquer vantagem pecuniária" (SÃO PAULO, 2000, p. 5). Ao mesmo tempo o artigo $8^{\circ}$ apresenta que "Não se aplicam os dispositivos desta lei complementar aos docentes eventuais e estagiários" (SÃO PAULO, 2000, p. 5).

A adoção da bonificação como uma forma 'artificial' de aumento dos rendimentos dos docentes é uma medida de flexibilização de seu salário. Apesar de acrescentar uma determinada quantia à remuneração total, o valor acrescido pelo bônus não é incorporado aos salários $^{v}$ nem aos vencimentos que determinam a arrecadação para a previdência social ${ }^{\mathrm{vi}}$.

Em 2001 foi realizada a primeira alteração referente à lei das bonificações dos docentes. No Decreto n. ${ }^{\circ} 46.167$, de 9 de outubro de 2001, no artigo $4^{\circ}$ é destacado que uma das condições para receber o bônus mérito seria "I - a frequência apresentada pelo docente durante o período letivo de 2000, no exercício de suas atribuições" (SÃO PAULO, 2001, p. 1), e no artigo $6^{\circ}$ "I - o número de ausências no período relativo aos meses de março, abril, agosto, setembro, outubro e novembro de 2000, totalizando 183 (cento e oitenta e três) dias letivos" (SÃO PAULO, 2001, p. 01). Ainda no inciso, "II - as faltas abonadas, justificadas e injustificadas, bem como as licenças e afastamentos de qualquer natureza, para o cômputo de ausências exceto os afastamentos previstos na Lei Complementar no 891" (SÃO PAULO, 2001, p. 5). Portanto, segundo o decreto, uma das condições para o recebimento do bônus era a assiduidade do docente ao longo do ano letivo.

Após as alterações no Decreto de 2001, outras três alterações, em 2008, 2009 e 2011, foram realizadas nas legislações que regulamentam as bonificações dos docentes paulistas. As principais reformas constantes nessas leis desencadearam as seguintes medidas: o recebimento integral da bonificação por resultado associado às metas; os indicadores que condicionariam o pagamento por bonificação e a alteração no tempo de trabalho do docente para atingir o salário do topo de carreira, uma vez que, enquanto na Lei Complementar $\mathrm{n}^{\circ}$ 836, de 30 de dezembro de 1997, o professor necessitava alcançar 5 níveis em 18 anos para atingir o topo, a Lei Complementar n. ${ }^{\circ} 1.143$, de 11 de julho de 2011, instituiu 8 faixas, que somente são atingidas após 24 anos de trabalho, caso o docente seja aprovado nas devidas avaliações ininterruptamente.

As legislações paulistas que destacamos promovem o envolvimento dos docentes no trabalho seguindo a lógica da 'gestão empresarial', cujos princípios têm presidido as políticas educacionais nos últimos 20 anos. Para Cassettari (2008, p. 8), apesar de os seus defensores anunciarem uma propaganda favorável à meritocracia, “[...] o pagamento por performance incentiva a competição entre professores ou escolas, o que pode minar a cooperação e o trabalho em equipe, indispensáveis para o funcionamento de qualquer instituição".

A inserção de uma série de avaliações com indicadores estabelecidos pelos técnicos da Secretária da Educação, com a finalidade de gerar o cálculo da bonificação, configurou-se na prática como estratégia, por um lado, de controle do trabalho dos professores e, por outro, como forma de camuflar o arrocho salarial. Os valores monetários distribuídos pelos bônus 
levaram os professores a 'assimilarem' com maior facilidade a defasagem dos salários percebidos. Para Oliveira (2003, p. 41) com essa manobra para ocultar o arrocho,

[...] os salários permaneceram sem reajustes ou com correções muito inferiores à inflação, e somente a fração variável teve alguma recomposição. Assim, por meio de estratégias de avaliação, o controle da disciplina do trabalho pelos governos tornou-se muito mais intenso, e as lutas dos sindicatos tornaram-se mais complexas. Do ponto de vista simbólico, os professores foram reiteradas vezes acusados de corporativismo, em um processo desqualificador que resultou na construção de uma imagem extremamente negativa para a categoria.

Portanto, os baixos reajustes salariais proporcionados pela Secretaria de Educação do Estado de São Paulo e o aprimoramento da expansão de reformas destinadas à ampliação de bonificação tem sido medidas inerentes à política paulista nos últimos 20 anos.

\section{CONSIDERAÇÕES FINAIS}

Neste trabalho tivemos o objetivo de verificar e analisar as categorias que caracterizam a precarização do trabalho docente, bem como as legislações federais e estaduais paulistas que norteiam o avanço do processo de precarização.

Após apresentarmos uma série de legislações que estão em vigor em nível federal e, em especial, no Estado de São Paulo, concluímos que a intensificação do trabalho docente, as formas flexíveis de contratação e o arrocho salarial são tendências na rede pública estadual paulista iniciadas nos anos de 1990.

Ressaltamos que dos anos 2000 até a atualidade ocorreu uma 'sofisticação perversa' na formulação de leis, decretos e resoluções estaduais paulistas, que tiveram a finalidade de ampliar a jornada de trabalho, flexibilizar as contratações e procrastinar os reajustes salariais dos docentes. E isso ocorreu com a implantação de métodos de controle e vigilância do trabalho, propiciados pelas inúmeras avaliações e pela bonificação por resultados.

Por conseguinte, ressalvamos a importância da luta dos professores, associações e sindicatos, com o apoio dos alunos, familiares e a sociedade de modo geral, contra as já estabelecidas e novas formas de precarização do trabalho docente no Estado de São Paulo. Várias reivindicações, tais como, o aumento de 75,33\% para equiparação salarial dos professores com as demais categorias com formação de nível superior; a implantação da jornada do piso; o desmembramento das salas superlotadas; a transformação do bônus em reajuste salarial etc. motivou a greve dos professores das escolas da rede pública paulista entre os meses de março e junho de 2015 (APEOESP, 2015).

O movimento realizado pelos professores paulistas em 2015 desvendou para a sociedade, entre outros problemas, as péssimas condições e a precarização do trabalho docente. Também ficou evidente que a conquista das reivindicações dos professores pela melhoria das condições de trabalho e pelo cumprimento de legislações vigentes como, por exemplo, a da jornada de trabalho estabelecida na lei do piso é absolutamente necessária para que o Estado de São Paulo possa oferecer um ensino gratuito, público e de qualidade para milhões de crianças e adolescentes. 


\section{REFERÊNCIAS}

ALVES, Giovanni. Dimensões da reestruturação produtiva: ensaios da sociologia do trabalho. Londrina: Práxis, 2007.

APEOESP. Professores decretam greve por tempo indeterminado. São Paulo: APEOESP, 2015. Disponível em: < http://goo.gl/u8OXds>. Acesso em: 07 mai. 2015.

APEOESP. Salário base PEB I e PEB II por jornada de trabalho. São Paulo: APEOESP, 2014. Disponível em: 〈http://goo.gl/ILBPk2>. Acesso em: 19 set. 2015.

ARANHA, Wellington Luiz Alves. Professores eventuais nas escolas estaduais paulistas: ajudantes de serviço geral da educação? 2007. 102 f. Dissertação (Mestrado em Educação) Faculdade de Ciências e Letras, Universidade Estadual Paulista, Araraquara, 2007.

Disponível em: < http://goo.gl/yMQcAk>. Acesso em: 24 mai. 2015.

BRASIL. Constituição (1988). Constituição da República Federativa do Brasil: texto constitucional promulgado em 5 de outubro de 1988, com as alterações adotadas pelas Emendas Constitucionais nos 1/1992 a 68/2011, pelo Decreto Legislativo n. 186/2008 e pelas Emendas Constitucionais de Revisão nos 1 a 6/1994. 35.ed. Brasília: Câmara dos Deputados, 2012. Disponível em: < http://goo.gl/wUgZP>. Acesso em: 13 set. 2014.

BRASIL. Decreto n. 3.048, de 6 de maio de 1999. Aprova o Regulamento da Previdência Social, e dá outras providências. Diário Oficial da União, Brasília, DF, Seção 1, p. 50, 1999. Disponível em: < http://goo.gl/jvw9lo>. Acesso em: 13 set. 2014.

BRASIL. Emenda Constitucional n. 19, de 04 de junho de 1998. Modifica o regime e dispõe sobre princípios e normas da Administração Pública, servidores e agentes políticos, controle de despesas e finanças públicas e custeio de atividades a cargo do Distrito Federal, e dá outras providências. Diário Oficial da União, Brasília, DF, Seção 1, p. 1, 1998. Disponível em: <http://goo.gl/cQJbu $>$. Acesso em: set. 2014.

BRASIL. Lei n. 8.745, de 09 de dezembro de 1993. Dispõe sobre a contratação por tempo determinado para atender a necessidade temporária de excepcional interesse público, nos termos do inciso IX do art. 37 da Constituição Federal, e dá outras providências. Diário Oficial da União, Brasília, DF, Seção 1, p. 1, 1993. Disponível em: 〈http://goo.gl/cyaqLF>. Acesso em: 13 set. 2014.

BRASIL. Lei n. 8.212, de 24 de julho de 1991. Dispõe sobre a organização da Seguridade Social, institui Plano de Custeio, e dá outras providências. Diário Oficial da União, Brasília, DF, Seção 1, p. 14801, 1991. Disponível em: 〈http://goo.gl/bjlvfW〉. Acesso em: 13 set. 2014.

BRASIL. Lei n. 11.738, de 16 de julho de 2008. Regulamenta a alínea 'e' do inciso III do caput do art. 60 do Ato das Disposições Constitucionais Transitórias, para instituir o piso salarial profissional nacional para os profissionais do magistério público da educação básica. Diário Oficial da União, Brasília, DF, Seção 1, p. 1, 2008. Disponível em: <http://goo.gl/17XRWW>. Acesso em: 13 set. 2014. 
CASSETTARI, Nathalia. Pagamento por performance na Educação Básica. In: $31^{\mathrm{a}}$ Reunião Anual da ANPED, 2008, Caxambu, MG. 31ª Reunião Anual da ANPED, 2008. v. 1. p. 115. Disponível em: 〈http://goo.gl/769TX1>. Acesso em: 16 set. 2014.

DEL PINO, Mauro Augusto Burkert; VIEIRA, Jarbas Santos; HYPOLITO, Álvaro Moreira. Trabalho docente, controle e intensificação: câmeras, novo gerencialismo e práticas de governo. In: FIDALGO, Fernando; OLIVEIRA, Maria Auxiliadoura; FIDALGO, Nara Luciene Rocha (Org.). A intensificação do trabalho docente: tecnologias e produtividade. Campinas: Papirus, 2009.

DIEESE. Boletim de Conjuntura n. 1. São Paulo: APEOESP, 2007.

DIEESE. Boletim de Conjuntura n. 2. São Paulo: APEOESP, 2011. Disponível em: <http://goo.gl/288tCm>. Acesso em: 16 set. 2014.

DIEESE. Salário mínimo nominal e necessário. São Paulo: DIEESE, 2014. Disponível em: <http://goo.gl/DRhge >. Acesso em: 19 set. 2015.

FERREIRA JUNIOR; Amarílio; BITTAR, Marisa. A ditadura militar e a proletarização dos professores. Educação e Sociedade, Campinas, SP, v. 27, n. 97, p. 1159-1179. set./dez. 2006. Disponível em: < http://goo.gl/tY3wyh>. Acesso em: 20 dez. 2012. ISSN 1678-4626.

GARCIA, Maria Manuela Alves; ANADON, Simone Barreto. Reforma educacional, intensificação e autointensificação do trabalho docente. Educação e Sociedade, Campinas, SP, v. 30, n. 106, p. 63-85. jan./abr. 2009. Disponível em: 〈http://goo.gl/pkKd8T〉. Acesso em: 16 set. 2014. ISSN 1678-4626.

INSTITUTO PAULO MONTENEGRO. Ser professor: uma pesquisa sobre o que pensa o docente das principais capitais brasileiras. Estudos e Pesquisas Educacionais, São Paulo, SP, n. 1. 2010. Disponível em: < http://goo.gl/8mO25H>. Acesso em: 16 set. 2014.

KUENZER, Acácia Zeneida; CALDAS, Andreia. Trabalho docente: comprometimento e desistência. In: FIDALGO, Fernando; OLIVEIRA, Maria Auxiliadoura; FIDALGO, Nara Luciene Rocha (Org.). A intensificação do trabalho docente: tecnologias e produtividade. Campinas: Papirus, 2009.

LAPO, Flavinês Rebolo; BUENO, Belmira Oliveira. Professores, desencanto com a profissão e abandono do magistério. Cadernos de Pesquisa, São Paulo, SP, n. 118, p. 65-88. mar. 2003. Disponível em: 〈http://goo.gl/xC41Fe〉. Acesso em: 10 fev. 2014. ISSN 0100-1574.

MONFREDINI, Ivanise. O regime de progressão continuada: as práticas escolares implementadas e as consequências para o trabalho e a profissão docente. In: MONFREDINI, Ivanise (Org.). Políticas educacionais, trabalho e profissão docente. São Paulo: Xamã, 2008.

MOURA, Carolina Baruel de. A precarização do trabalho docente nas escolas estaduais paulistas. 2013. 127 f. Dissertação (Mestrado em Educação) - Faculdade de Filosofia e Ciências, Universidade Estadual Paulista, Marília, SP, 2013. Disponível em:

$<$ https://goo.gl/SWYNu1>. Acesso em: 24 mai. 2015.

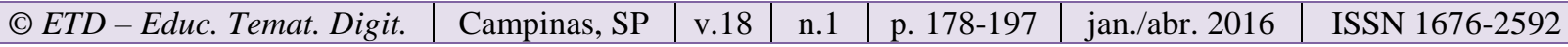


OLIVEIRA, Marco Antônio. Tendências recentes das negociações coletivas no Brasil. In: PRONI, Marcelo Weishaupt; HENRIQUE, Wilnês (Org.). Trabalho, mercado e sociedade: o Brasil nos anos 90. São Paulo: Editora da Unesp, 2003, p. 323-355.

PESSANHA, Eurize Caldas. Ascensão e queda do professor. São Paulo: Cortez, 2001.

SÃO PAULO. Decreto n. 59.448, de 19 de agosto de 2013. Altera e acrescenta dispositivos ao Decreto n. 55.078, de 25 de novembro de 2009, que dispõe sobre as jornadas de trabalho do pessoal docente do Quadro do Magistério e dá providências correlatas. Diário Oficial do Estado, São Paulo, SP, Seção I, p. 1, 2013. Disponível em: < http://goo.gl/bJzPnm>. Acesso em: 18 mai. 2014.

SÃO PAULO. Decreto n. 46.167, de 9 de outubro de 2001. Regulamenta o Bônus Mérito instituído às classes de docentes do Quadro do Magistério. Diário Oficial do Estado, São Paulo, SP, Seção I, p. 1, 2001. Disponível em: < http://goo.gl/UCYKyE>. Acesso em: 13 set. 2014.

SÃO PAULO. Decreto n. 24.948, de 3 de abril de 1986. Termos descritivos: Quadro do magistério; classes de cargos; professores. Disciplina as substituições nos impedimentos temporários dos integrantes do Quadro do Magistério e dá providências correlatas. Diário Oficial do Estado, São Paulo, SP, v. 96, n. 63, 1986. Disponível em: 〈http://goo.gl/d8Pac4 >. Acesso: 18 mai. 2014.

SÃO PAULO. Lei Complementar n. 1.093 de 16 de julho de 2009. Dispõe sobre a contratação por tempo determinado de que trata o inciso X do artigo 115 da Constituição Estadual e dá outras providências correlatas. Diário Oficial do Estado, São Paulo, SP, Seção I, p. 1, 2009. Disponível em: < http://goo.gl/W7Eao>. Acesso em: 18 mai. 2014.

SÃO PAULO. Lei Complementar n. 1.143, de 11 de julho de 2011. Dispõe sobre a reclassificação de vencimentos e salários dos integrantes do Quadro do Magistério da Secretaria da Educação, e dá providências correlatas. Diário Oficial do Estado, São Paulo, SP, Seção I, p. 01, 2011.

SÃO PAULO. Lei Complementar n. 891, de 28 de dezembro de 2000. Institui Bônus Mérito as classes de docentes do Quadro do Magistério, e dá outras providências. Diário Oficial do Estado, São Paulo, SP, Seção I, p. 5, 2000. Disponível em: 〈 http://goo.gl/dhXNIK〉. Acesso em: 13 set. 2014.

SÃO PAULO. Resolução SE n. 134, de 16 de dezembro de 2003. Dispõe sobre o processo anual de atribuição de classes e aulas ao pessoal docente do Quadro do Magistério. Diário Oficial do Estado, São Paulo, SP, Seção I, p. 1, 2004. Disponível em: < http://goo.gl/8rdqfe $>$. Acesso: 18 mai. 2014.

SILVA JÚNIOR, Celestino Alves. A escola pública como local de trabalho. São Paulo: Cortez, Autores Associados, 1990.

SOUZA, Aparecida Neri. As políticas educacionais para o desenvolvimento e o trabalho docente. 1999. 216 f. Tese (Doutorado em Educação) - Faculdade de Educação, Universidade Estadual de Campinas, Campinas, SP, 1999. Disponível em:

< http://goo.gl/9Ikwtx $>$. Acesso em: 24 mai. 2015.

\begin{tabular}{l|l|l|l|l|l|l}
\hline (C) ETD -Educ. Temat. Digit. & Campinas, SP & v.18 & n.1 & p. 178-197 & jan./abr. 2016 & ISSN 1676-2592
\end{tabular} 
TAKAHASHI, Fábio. Apesar de concursos, SP contrata mais professores temporários. Folha de São Paulo, São Paulo, SP, 15 mai. 2014. Disponível em: 〈http://goo.gl/i1GWbK〉. Acesso em: 24 mai. 2015.

TORRES, Rosa Maria. Melhorar a qualidade da educação básica? As estratégias do Banco Mundial. In: TOMMASI, Lívia de; WARDE, Mirian Jorge; HADDAD, Sérgio (Org.). O Banco Mundial e as políticas educacionais. São Paulo: Cortez, 2007.

VIANNA, Cláudia. Os nós do "nós": crise e perspectivas da ação coletiva docente em São Paulo. São Paulo, Xamã, 1999.

VICENTINI, Paula Perin; LUGLI, Rosário Genta. História da profissão docente no Brasil: representações em disputa. São Paulo: Cortez, 2009.

VIEITEZ, Candido Giraldez; DAL RI, Neusa Maria. Educação no movimento social: a luta contra a precarização do ensino público. In: LIMA, Francisca das Chagas Silva; SOUZA, Jhonatan Uelson Pereira; CARDOZO, Maria José Pires Barros (Org.). Democratização e educação pública: sendas e veredas. São Luís: EDUFMA, v. 1, 2011, p. 133-165. Disponível em: <http://goo.gl/NVDMQq>. Acesso em: 24 mai. 2015.

\section{Como citar este documento:}

PIOVEZAN, Patricia Regina; DAL RI, Neusa Maria. A precarização do trabalho docente no estado de São Paulo: vinte anos de reformas. ETD - Educação Temática Digital, Campinas, SP, v. 18, n. 1, p. 178-197, abr. 2016. ISSN 1676-2592. Disponível em:

<http://periodicos.sbu.unicamp.br/ojs/index.php/etd/article/view/8635567>. Acesso em: 06 abr. 2016. doi: 〈http://dx.doi.org/10.20396/etd.v18i1.8635567>. 
' A esse respeito ver o trabalho de Celestino Alves da Silva Júnior, A escola pública como local de trabalho. São Paulo: Cortez, Autores Associados, 1990.

ii As principais entidades que integraram o Fórum foram: Associação Nacional de Pesquisa e Pós- graduação em Educação (ANPEd), Associação Nacional de Educação (ANDE), Associação Nacional de Política e Administração da Educação (ANPAE), Sociedade Brasileira para o Progresso da Ciência (SBPC), Sociedade de Estudos e Atividades Filosóficas (SEAF), Confederação de Professores do Brasil (CPB), Centro de Estudos Educação e Sociedade (CEDES), Confederação Geral de Trabalhadores (CGT), Central Única de Trabalhadores (CUT), Federação Nacional dos Orientadores Educacionais (FENOE), Federação das Associações dos Servidores das Universidades Brasileiras (FASUBRA), Ordem dos Advogados do Brasil (OAB ), União Brasileira de Estudantes Secundaristas (UBES ), União Nacional dos Estudantes (UNE)

iii Conforme o Instituto Paulo Montenegro (2010, p. 13-14) “[...] é possível perceber também professores e professoras completamente envolvidos com suas atividades fora de seu horário de trabalho e, com muita frequência, durante sua hora de lanche. Em muitos momentos, chegam à escola antes do horário de início e saem depois do horário de término, além de, muitas vezes, gastarem horas de trabalho em casa, durante a noite".

iv As especificações referentes a esse decreto serão abordadas com maiores detalhes nas próximas páginas desse trabalho.

$\checkmark$ As bonificações não podem integrar o salário de contribuição do servidor, de acordo com o previsto na Lei 8.212, de 12 de julho de 1991, que assim dispõe sobre o assunto: "Art. 28. $\S 9^{\circ}$ - Não integram o salário-decontribuição para os fins desta Lei, exclusivamente: e) as importâncias: 7. recebidas a título de ganhos eventuais e os abonos expressamente desvinculados do salário" (BRASIL, 1991, p. 17).

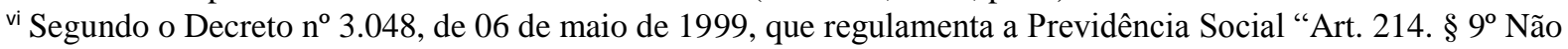
integram o salário-de-contribuição, exclusivamente: j) ganhos eventuais e abonos expressamente desvinculados do salário por força de lei” (BRASIL, 1999, p. 100). 